\title{
HUBUNGAN ANTARA IMEJ KORPORAT USAHAWAN MUSLIM DAN PEMBAYARAN ZAKAT PERNIAGAAN DI DAERAH SEPANG, SELANGOR
}

\section{The Relationship between Corporate Image of Muslim Entrepreneurs and Business Zakāh Payment in Sepang, Selangor}

\author{
Hairunnizam Wahid ${ }^{1}$ \\ Abdul Halim Abu Bakar ${ }^{2}$ \\ Sanep Ahmad A $^{3}$
}

\begin{abstract}
This study reveals that the awareness on the obligation to pay zakāh business among the Muslim entrepreneurs is still marginal. This study hypothesizes that the motivation of paying zakāh business among the Muslim entrepreneurs has a strong connection with their tendency to promote their business and corporate image. Interestingly, the Muslim entrepreneurs were interested to share their action in paying zakāh as the way to
\end{abstract}

1 Senior Lecturer, School of Economics, Faculty of Economics and Business, The National University of Malaysia, 43600 Bangi, hairun@ukm.edu.my

2 Master Candidate, School of Economics, Faculty of Economics and Business, The National University of Malaysia, 43600 Bangi; Zakat Officer at Lembaga Zakat Selangor,abdulhalimab@gmail.com

3 Associate Professor, School of Economics, Faculty of Economics and Business, The National University of Malaysia, 43600 Bangi, nep@ukm.edu.my 
market their product or organization that finally will increase their profit. Therefore, this factor has been considered as an important factor that would potentially increase the amount of zakāh collected by Lembaga Zakat Selangor (LZS) every year. Thus, this study aims to analyze the factor of corporate image and other potential variables that probably influence the payment of zakāh business among the Muslim entrepreneurs in Sepang, Selangor. This study has studied several factors that potentially influencing the awareness of paying zakāh business including entrepreneur attitudes, corporate image, and zakāh's service provided by the zakāh institutions, the staff of the zakāh institutions and also the fatwā of zakāh using logistic regression. The result shows that the variable of corporate image through paying zakāh business is an important and significant factor that motivates the Muslim entrepreneurs to pay zakāh. However the study shows that corporate image has a negative relationship with motivation of paying zakāh business. Several recommendations have been discussed in this study.

Keywords: zakāh business, corporate image, Muslim entrepreneurs

\section{PENGENALAN}

Zakat daripada segi bahasa Arab bermaksud suci, kembang, subur, bertambah dan bersih. Seseorang yang menunaikan zakat sudah tentulah mengharapkan harta dan perniagaannya terus bertambah, subur, suci dan bersih. Zakat daripada segi istilah syarak pula bermaksud mengeluarkan sejumlah harta tertentu, dengan syarat tertentu dan diberikan kepada golongan tertentu. ${ }^{4}$ Zakat merupakan rukun Islam yang ketiga dan amat unik kerana mempunyai campuran aspek ibadah dan muamalat di dalamnya. Adalah tidak wajar jika urusan zakat dianggap sebagai kefardhuan yang berbentuk individu semata-mata dan hanya dibincangkan dalam bahagian ibadah. Namun, zakat juga perlu dikupas dalam aspek kenegaraan dan termasuk dalam sistem kewangan sesebuah negara. ${ }^{5}$ Ini bermakna, bagi melengkapkan dan menyempurnakan ibadah ini, seseorang tidak boleh lari daripada berurusan atau bermuamalat dengan beberapa pihak lain seperti pemerintah, badan zakat atau amil dan masyarakat. Dalam Islam,

$4 \quad$ Zulkifli Mohamad al-Bakri, Ahkam wa Fatawa al-Zakah, Pelbagai Hukum dan Fatwa Zakat (Bandar Baru Bangi: Darul Syakir Enterprise, 2010), 7-9.

5 Mujaini Tarimin, Kontinuiti Pembangunan Zakat di Malaysia (Shah Alam: Lembaga Zakat Selangor, 2011), 91. 
zakat terbahagi kepada dua jenis sahaja iaitu zakat fitrah dan zakat harta. ${ }^{6} \mathrm{Di}$ peringkat awal perkembangan Islam, jenis harta zakat adalah tertakluk kepada keadaan dan jenis aktiviti ekonomi yang wujud pada masa tersebut. Aktiviti ekonominya ialah tanaman, ternakan, perniagaan, simpanan emas, simpanan perak, kunuz dan rikaz. Syarat-syarat yang mewajibkan seseorang berzakat ada 5 iaitu Islam, merdeka (bukan hamba), harta yang sempurna milik, cukup hawl (tempoh/tahun) dan cukup nișab. ${ }^{7}$ Golongan yang berhak menerima zakat berdasarkan firman Allah SWT dalam al-Quran:

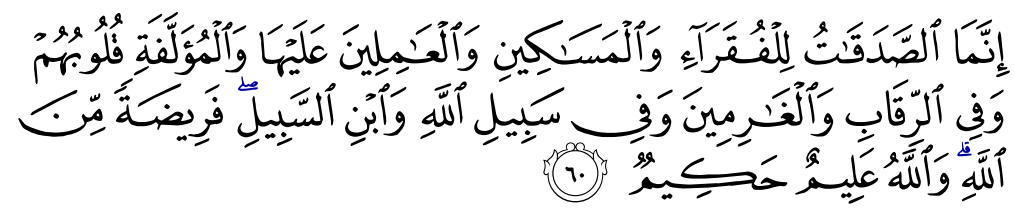

"Sesungguhnya zakat-zakat itu hanyalah untuk orang-orang fakir, orang-orang miskin, pengurus-pengurus zakat, para muallaf yang dipujuk hatinya, untuk memerdekakan hamba, orang-orang yang berhutang, untuk jalan Allah dan untuk mereka yang sedang di dalam perjalanan, sebagai suatu ketetapan yang diwajibkan Allah, dan Allah Maha Mengetahui lagi Maha Bijaksana."

(Surah al-Tawbah, 9: 60)

Ayat ini menunjukkan bahawa golongan yang berhak menerima zakat hanya lapan golongan sahaja. Jumhur fuqaha' berpendapat, tidak harus diberikan kepada selain daripada yang dinaskan al-Quran. Namun begitu, amil yang dikenali badan zakat pada masa awal Islam sehingga kini tetap berada di dalam senarai lapan golongan asnaf yang juga dianggap penerima harta zakat walaupun mereka bertindak sebagai sebuah pihak yang mengurus harta zakat.

Pada Butiran 1, Senarai ke-2, Jadual ke-9, Perlembagaan Persekutuan menyatakan bahawa, zakat dan perkara lain tentang agama Islam yang seumpamanya di samping waqaf, pemberian agama Islam dan khairat, institusi, amanah dan institusi khairat yang dijalankan semuanya sekali dalam negeri dan lain-lainnya terletak di bawah bidang kuasa negeri-negeri. Kerajaan negeri mempertanggungjawabkan Majlis Agama Islam Negeri bagi mengendalikan segala urusan berkaitan agama di negeri-negeri termasuklah urusan pentadbiran serta pengurusan pungutan dan agihan zakat. ${ }^{8}$ Di negeri

6 Jabatan Kemajuan Islam Malaysia, Panduan Zakat di Malaysia (Kuala Lumpur: JAKIM, 2001), 3-4.

7 Ahmad Abdul Aziz Al-Mazini, Panduan Mengeluarkan Zakat (Petaling Jaya: alRahmaniah, 1989), 44-54.

8 Mujaini Tarimin, Kontinuiti Pembangunan Zakat di Malaysia, 93. 
Selangor, Lembaga Zakat Selangor (LZS) telah ditubuhkan semenjak tahun 1995 bagi melakukan urusan kutipan dan agihan zakat. Berpandukan Seksyen 86, Enakmen Pentadbiran Agama Islam Negeri Selangor 2003, Majlis Agama Islam Selangor (MAIS) melalui perbadanan di bawahnya iaitu LZS adalah satu-satunya badan yang dilantik untuk membuat kutipan dan pengagihan zakat atau fitrah di Selangor termasuk zakat perniagaan. LZS (MAIS) berupaya meningkatkan kecemerlangannya sebagai institusi zakat yang disegani dalam tempoh dua dekad dengan mempergiatkan gerak kerja dakwah bagi memastikan lebih ramai masyarakat menunaikan rukun Islam ini. Manakala, pengagihan zakat juga ditambah baik agar menyeluruh dan berkesan kepada lapan asnaf yang ditetapkan dalam al-Quran melalui lima program pembangunan utama asnaf iaitu program pembangunan sosial, pendidikan, ekonomi, insan dan pembangunan institusi agama. Berpandukan motto 'Meneraju Perubahan', LZS (MAIS) sentiasa berusaha memberikan perkhidmatan terbaik kepada para pelanggannya iaitu pembayar dan penerima zakat. ${ }^{9}$ Dibantu dengan tenaga lebih 400 orang warga kerja serta disokong oleh 25 buah cawangan LZS di seluruh Selangor, LZS (MAIS) terus menjalankan amanah sebagai amil yang mempunyai integriti, jujur dan telus dalam melaksanakan tanggungjawabnya.

Sesebuah syarikat milik orang Islam atau usahawan muslim sangat memerlukan gambaran imej yang baik dan sempurna dalam kalangan masyarakat dan pemerintah walaupun dalam hal pembayaran zakat. Saban tahun masyarakat disajikan dengan hebahan mengenai pembayaran zakat oleh usahawan Muslim sama ada melalui media elektronik, media sosial dan media cetak. Mereka ingin dikenali sebagai golongan yang mengutamakan dan mengambil berat terhadap kebajikan masyarakat berbanding pesaing. Mereka juga yakin, dengan membayar zakat mampu meningkatkan hasil dan memanjangkan jangka hayat perniagaan. Usahawan Muslim juga amat yakin bahawa, jika pelanggan tahu mereka membayar zakat, kesetiaan dan keyakinan pelanggan akan lebih tinggi. Malah, usahawan Muslim beranggapan bahawa mereka akan lebih beriltizam, bermotivasi dan bersemangat apabila pelanggan mengetahui mereka telah menunaikan tanggungjawab bersifat sosial iaitu membayar zakat perniagaan. Persoalannya, adakah kemungkinan faktor imej korporat mempengaruhi pembayaran zakat usahawan Muslim kepada LZS? Kebanyakan kajian yang sedia ada hanya melihat aspek imej korporat institusi $\mathrm{LZS}^{10}$ dan kesannya dalam mempengaruhi pembayaran zakat kepada institusi

$9 \quad$ Lembaga Zakat Selangor, http://www.e-zakat.com.my/sejarah-lzs/, dicapai pada 5 November 2014.

10 Ram Al Jaffri Saad, Kamil Md. Idris \& Zainol Bidin, 'Peraturan Pembayaran Zakat Kepada Institusi Zakat: Sikap Peniaga dan Kesannya Terhadap Gelagat Pembayaran Zakat Perniagaan,' Jurnal Syariah, 17/3 (2009): 610. 
tersebut dan bukannya mengkaji faktor imej korporat usahawan itu sendiri atau meningkatkan imej korporat organisasi perniagaan sebagai motivasi untuk membayar zakat.

Justeru, kajian ini bertujuan untuk mengenalpasti sejauh mana faktor imej korporat mempengaruhi pembayaran zakat perniagaan usahawan. Selain itu, kajian ini melihat pengaruh empat faktor lain seperti sikap individu, institusi zakat, kakitangan zakat dan penguatkuasaan fatwa serta undang-undang zakat dapat mempengaruhi pembayaran zakat perniagaan. Kajian ini juga cuba menunjukkan bahawa imej korporat usahawan yang membayar zakat adalah salah satu faktor terpenting yang mempengaruhi pembayaran zakat perniagaan. Skop kajian ini tertumpu kepada kaitan pembayaran zakat perniagaan dengan imej korporat usahawan Muslim di Sepang, Selangor. Daerah Sepang dipilih memandangkan ia merupakan antara daerah yang mempunyai nisbah usahawan Islam berbanding usahawan bukan Islam yang agak tinggi di negeri Selangor. Hipotesis kajian ini melihat bahawa seseorang usahawan itu telah dan akan membayar zakat perniagaan atas faktor imej korporat sebagai pencetus motivasi untuk membayar zakat.

\section{KAJIAN LEPAS}

Amalan berzakat boleh membiasakan diri pengeluarnya bersifat pemurah, suka beribadah dan merasai hartanya semakin bertambah, bukan semakin berkurang. ${ }^{11}$ Hikmah ini menggambarkan bahawa niat permulaan dan pengaruh yang kuat dalam berzakat adalah sikap semulajadi individu itu sendiri. Pihak terpenting yang menguruskan zakat adalah para amil iaitu pegawai dan petugas yang menerima upah hasil daripada pekerjaan mereka sebagai pengurus harta zakat. ${ }^{12}$ Dari segi siyāsah dan mașlahah, zakat merupakan pemangkin kepada ekonomi umat Islam. Peraturan dan undang-undang yang telah ditetapkan oleh pemerintah atau $\bar{u} l \bar{\imath}$ al-amr adalah demi menjaga hak dan kepentingan zakat tersebut. Walaupun daripada segi syarak, mengagihkan zakat secara persendirian tanpa melalui pemerintah adalah sah sekiranya diagihkan kepada asnaf yang layak, tetapi perbuatan melanggar peraturan dan undang-undang pemerintah dalam perkara kebaikan adalah berdosa, kerana dalam Islam patuh dan taat kepada pemerintah atau $\bar{u} l \bar{l}$ al-amr dalam perkara kebaikan adalah wajib. ${ }^{13}$

11 Zulkifli Mohamad al-Bakri, Ahkam wa Fatawa al-Zakah, Pelbagai Hukum dan Fatwa Zakat, 15.

12 Zulkifli Mohamad al-Bakri, Ahkam wa Fatawa al-Zakah, Pelbagai Hukum dan Fatwa Zakat, 77.

13 Warta Kerajaan Negeri Selangor, 2007. 
Perkataan imej ditakrifkan secara terus dengan istilah cerminan, bayangan dan gambaran yang terlintas pada fikiran. Istilah yang lebih tepat ialah maruah, nama baik, prestij dan tanggapan di mata umum. ${ }^{14}$ Perkataan imej berasal daripada perkataan Latin "Imago" yang bermakna meniru. Manakala imej juga dapat ditakrifkan sebagai konsep seseorang, institusi dan negara yang terkenal melalui komunikasi media. ${ }^{15}$ Imej sebagai sistem yang mengkategorikan kumpulan seseorang mengikut tanda dan label. ${ }^{16}$ Imej adalah pengetahuan, penilaian dan tindakan yang dipersepsikan dari satu objek sama ada ia "animate" atau tidak "animate". Kognitif atau pengetahuan ini terdiri daripada idea, konsepsi, persepsi dan sikap, pendapat, nilai serta kepercayaan yang sering kita golongkan sebagai pengetahuan. Imej juga adalah hasil kumulatif daripada interaksi pengalaman lepas, pengetahuan, sikap dan perlakuan seseorang terhadap sesuatu objek. ${ }^{17}$ Terdapat kajian lain yang menganggap bahawa imej terdiri daripada komponen kognitif iaitu sebarang repentasi pemikiran yang mempunyai kualiti deria dan bukan semata-mata peniruan (imitation) tetapi ia adalah pecahan-pecahan ingatan rekonstruksi, interpretasi semula simbol yang mewakili objek perasaan ataupun idea. ${ }^{18}$

Justeru, identiti, imej dan reputasi adalah agenda utama organisasi melalui kegiatan komunikasi korporat. Ketika era globalisasi, imej dilihat sebagai salah satu elemen yang sedang diperkuatkan oleh mana-mana organisasi. Masyarakat melihat produk dan perkhidmatan yang ditawarkan oleh organisasi adalah dalam pakej yang lebih menyeluruh. ${ }^{19}$ Imej korporat akan menggambarkan potensinya dalam mencapai matlamat, kejayaan, kualiti dan kredibiliti. Organisasi terpaksa menerima kenyataan bahawa orang awam begitu prihatin terhadap imej korporat. Ini kerana imej yang baik dapat menarik perhatian awam keseluruhan serta menarik minat mereka

14 'Pusat Rujukan Persuratan Melayu,' Dewan Bahasa dan Pustaka, http://prpm. dbp.gov.my/Search.aspx?k=imej\#, dicapai pada 16 Mac 2016.

15 Webster, J.G \& Wakshlag J.J., 'A Theory of Television Program Choice,' Communication Research, 10/4 (1983): 430-446.

16 Merril, J.C., 'The Image of the United States in ten Mexican Dailies,' Journalism \& Mass Communication Quarterly, 39/2 (1962): 203-209.

17 Bahtiar M., Hassan A. B. \& Nik Adzrieman A. R., 'Relationship Between Corporate Identity and Corporate Reputation: A Case of A Malaysian Higher Education Sector,' Jurnal Manajemen Pemasaran, 2/2 (2007): 81-89.

18 Horowitz M.J., Image Formation and Cognition (US: Appleton Century Crofts, 1970), 1.

19 Bahtiar M., Hassan A. B. \& Nik Adzrieman A. R., 'Relationship Between Corporate Identity and Corporate Reputation: A Case of A Malaysian Higher Education Sector,' 81-89. 
untuk menggunakan perhidmatan atau produk yang ditawarkan. Berdasarkan laporan oleh Opinion Research Corporation (ORC) mendapati imej korporat adalah bahagian penting yang memasarkan syarikat dan produknya. Kajian yang dilakukan mendapati 97 peratus maklumbalas daripada pengurus kanan dan pertengahan mengakui imej adalah pengukuran yang signifikan dalam menentukan kejayaan dan kegagalan organisasi. ${ }^{20}$

Kajian yang dilakukan mendapati setiap organisasi memerlukan identiti korporat untuk terus bertahan dalam jangka panjang. Identiti ini akan berkembang dalam unjuran satu imej positif yang akan meningkatkan keyakinan orang awam mengenai kualiti dan prestasi organisasi. Walau bagaimanapun, kajian tersebut bertujuan untuk mengenal pasti identiti korporat dan reputasi institusi pengajian tinggi (IPT) iaitu Universiti Utara Malaysia (UUM) daripada bakal pelanggan di masa hadapan. Secara khusus, kajian beliau menguji hubungan antara identiti korporat dan reputasi korporat di sektor pendidikan tinggi Malaysia. Pelbagai ujian yang telah dibuat menunjukkan bahawa terdapat hubungan positif yang signifikan antara identiti korporat dan reputasi korporat. ${ }^{21}$

Manakala terdapat kajian lain bertujuan untuk meneroka dan mengkaji sikap usahawan terhadap peraturan zakat di negeri Kedah. Beliau menyenaraikan faktor sikap dan undang-undang sebagai punca seseorang usahawan itu ingin menunaikan zakat. ${ }^{22}$ Namun, terdapat kajian menumpukan isu bocoran pembayaran zakat. Pengkaji ini mengemukakan beberapa cadangan faktor lain bagi meningkatkan kepuasan individu iaitu prestasi, nama baik badan zakat, ketelusan dan agihan yang produktif. ${ }^{23}$ Beberapa faktor yang dinyatakan pengkaji sebelum ini turut digunakan dalamkajianini. Kewujudan isu lain seperti masih ramai masyarakat Islam masih belum menunaikan zakat pendapatan dan apakah faktor-faktor penyebab kepada perkara tersebut turut dikaji oleh beberapa pengkaji lain. Terdapat satu kajian menggunakan analisis regresi menunjukkan bahawa faktor demografi seperti umur, taraf perkahwinan dan

20 Marken, G. A., 'Corporate Image: We All Have One, But Few Work to Protect and Project It,' Public Relations Quarterly, 35/1 (1990): 21-24

21 Bahtiar M., Hassan A. B. \& Nik Adzrieman A. R., 'Relationship Between Corporate Identity and Corporate Reputation: A Case of A Malaysian Higher Education Sector,' 81-89.

22 Ram Al Jaffri Saad, Kamil Md. Idris \& Zainol Bidin, 'Peraturan Pembayaran Zakat Kepada Institusi Zakat: Sikap Peniaga dan Kesannya Terhadap Gelagat Pembayaran Zakat Perniagaan,' 607-630.

23 Sanep Ahmad \& Hairunnizam Wahid, 'Penerimaan dan Tanggapan Masyarakat Terhadap Sumber Zakat Harta yang Diikhtilaf,' Islamiyyat, 27 (2005): 45-65. 
pendapatan adalah signifikan mempengaruhi pembayaran zakat pendapatan di samping mekanisma pembayaran zakat pendapatan melalui potongan gaji. ${ }^{24}$ Namun terdapat kajian yang dibuat mengutarakan tentang persepsi segelintir masyarakat yang masih beranggapan bahawa pengurusan LZS dalam aspek agihan masih dianggap kurang memuaskan. ${ }^{25}$ Ia rentetan kepada kajian lain yang mengenalpasti bahawa, masyarakat Islam dikatakan masih tidak berpuas hati dengan pengurusan zakat oleh LZS terutamanya ketidakyakinan segelintir individu dengan kesungguhan LZS dalam mengurus agihan zakat. ${ }^{26}$

Terdapat beberapa kajian lain yang mengkaji zakat daripada pelbagai perspektif termasuklah aspek maqāșid al-Syarī'ah dan keberkesanan agihan zakat, ${ }^{27}$ penerokaan sumber-sumber zakat yang ada di Malaysia dan memahami keperluan pemeluasan asas zakat, ${ }^{28}$ kaedah perakaunan zakat perniagaan yang diamalkan di Malaysia serta kaedah taksiran zakat perniagaan yang dibuat oleh badan zakat negeri-negeri di Malaysia, ${ }^{29}$ isu dalam sistem agihan dana zakat seperti kajian terhadap faktor yang mempengaruhi ketidakcekapan yang berlaku melalui persepsi pengurusan pertengahan dan atasan, ${ }^{30}$ kajian tentang potensi pembayaran dan kutipan zakat di Malaysia, ${ }^{31}$ penerimaan dan tanggapan masyarakat terhadap sumber zakat yang diikhtilaf, ${ }^{32}$ pengagihan

24 Hairunnizam Wahid, Sanep Ahmad \& Mohd Ali Mohd Noor, 'Kesedaran Membayar Zakat Pendapatan di Malaysia,' Islamiyyat, 29 (2007): 53-70.

25 Hairunnizam Wahid, Sanep Ahmad \& Radiah Abdul Kader, 'Pengagihan Zakat oleh Institusi Zakat di Malaysia: Mengapakah Masyarakat Islam Tidak Berpuashati?’ Jurnal Syariah, 17/1 (2009): 89-112.

26 Sanep Ahmad \& Hairunnizam Wahid, 'Persepsi Agihan Zakat dan Kesannya Terhadap Pembayaran Zakat Melalui Institusi Formal,' Jurnal Ekonomi Malaysia, 39 (2005): 53-69.

27 Rosbi Abd Rahman \& Sanep Ahmad, 'Pengukuran Keberkesanan Agihan Zakat; Perspektif Maqasid Syariah,' Prosiding Persidangan Antarabangsa Ke-7, Tawhidi Epistemologi: Zakat and Waqf Economy (Bangi, 2010).

28 Arifin Md. Salleh et al., Asas Sumber-Sumber Zakat di Malaysia: Satu Penerokaan (Alor Gajah: URDC UiTM, 2006), vii.

29 Zahri Hamat, 'Perakaunan Zakat Perniagaan di Malaysia: Satu Kajian Rintis Pendapat Cendekiawan Zakat,' (Tesis PhD, Pusat Pengajian Sains Kemasyarakatan, USM Pulau Pinang, 2007), xv.

30 Azizah Dolah et al., Kajian Terhadap Amalan Perakaunan Pengurusan dalam Aspek Agihan Dana Zakat dari Perspektif Pengurus Zakat (Shah Alam: IRDC UiTM, 2004), 4-6.

31 Abdul Hakim Amir Osman, 'Potensi Pembayar dan Kutipan Zakat di Malaysia,' (Kertas Kerja Pembentangan, Konvensyen Zakat dan Cukai Peringkat Kebangsaan di PWTC, Kuala Lumpur, 22-24 Mei 2007).

32 Sanep Ahmad \& Hairunnizam Wahid, 'Persepsi Agihan Zakat dan Kesannya Terhadap Pembayaran Zakat Melalui Institusi Formal,' Jurnal Ekonomi Malaysia, 39 (2005): 53-69. 
zakat kepada lapan asnaf, ${ }^{33}$ persepsi amil dan penerima zakat terhadap cadangan melokalisasikan pengagihan zakat, ${ }^{34}$ pemantapan sistem zakat dan cukai ke arah kemajuan ekonomi ummah ${ }^{35}$ dan peranan agihan zakat dalam meningkatkan tahap ekonomi ummah. ${ }^{36}$ Kajian-kajian tersebut bertujuan untuk meningkatkan kesedaran masyarakat terhadap kewajipan berzakat agar jumlah kutipan zakat dapat dipertingkatkan seterusnya menambahbaik aspek kualiti hidup asnaf zakat terutamanya golongan fakir dan miskin dengan meningkatkan agihan zakat serta menyediakan pelbagai bantuan kepada mereka. Namun kajian berkenaan aspek imej korporat usahawan Muslim dan hubungannya dengan pembayaran zakat perniagaan belum lagi dilakukan setakat ini.

Rajah 1: Faktor Imej Korporat Organisasi Perniagaan

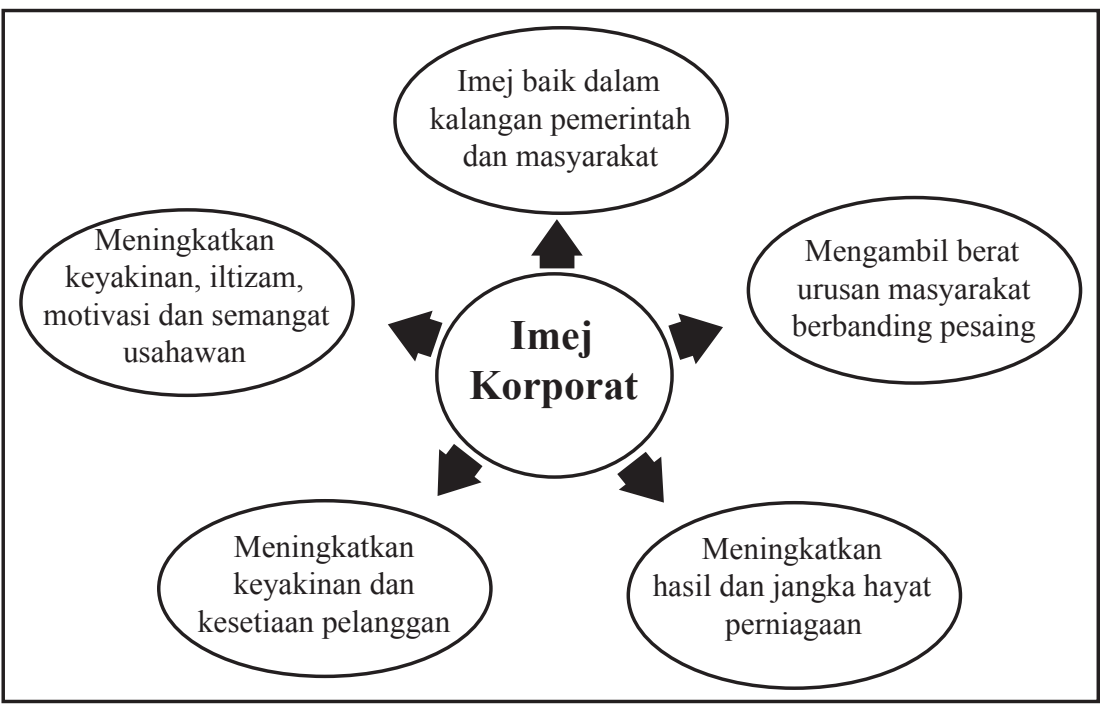

33 Hairunnizam Wahid, Sanep Ahmad \& Radiah Abdul Kader, 'Pengagihan Zakat oleh Institusi Zakat kepada Lapan Asnaf: Kajian di Malaysia,' Jurnal Pengurusan JAWHAR, 4/1 (2010): 141-170.

34 Hairunnizam Wahid \& Radiah Abdul Kader, 'Localization of Malaysian Zakat Distribution: Perceptions of Amil and Zakat Recipients,' Proceedings of Seventh International Conference. The Tawhidi Epistemology: Zakat and Waqf Economy, ed. Abdul Ghafar et al. (Bangi: UKM, 2010), 461-484.

35 Mahmood Zuhdi Abd. Majid, 'Pemantapan Sistem Zakat dan Cukai ke Arah Kemajuan Ekonomi Ummah,' (Kertas Kerja Pembentangan, Konvensyen Zakat \& Cukai Peringkat Kebangsaan di PWTC, Kuala Lumpur, 22-24 Mei 2007).

36 Patmawati Ibrahim, 'Peranan Agihan Zakat dalam Meningkatkan Tahap Ekonomi Ummah,' (Kertas Kerja Pembentangan, Konvensyen Zakat dan Cukai Peringkat Kebangsaan di PWTC, Kuala Lumpur, 22-24 Mei 2007). 
Sumber: Bahtiar M. et al., 'Relationship Between Corporate Identity and Corporate Reputation: A Case of A Malaysian Higher Education Sector,' Jurnal Manajemen Pemasaran, 2/2 (2007): 81-89.

Justeru, kajian ini merumuskan imej korporat sesebuah organisasi adalah bergantung kepada lima aspek utama iaitu (1) imej baik dalam kalangan pemerintah dan masyarakat; (2) mengambil berat urusan masyarakat berbanding pesaing, (3) meningkatkan hasil dan jangka hayat perniagaan, (4) meningkatkan keyakinan dan kesetiaan pelanggan; dan (5) meningkatkan keyakinan, iltizam, motivasi dan semangat usahawan (Rujuk Rajah 1). Kajian ini mengkaji faktor imej korporat sebagai faktor utama dan signifikan dalam mempengaruhi pembayaran zakat perniagaan olehusahawan Muslim di Sepang, Selangor selain empat faktor lain seperti faktor sikap, badan zakat, kakitangan dan undang-undang atau fatwa. Kajian ini menjangkakan kesemua faktor adalah berhubungan secara positif dengan kebarangkalian membayar zakat perniagaan. Kajian ini dijangka boleh membantu untuk meningkatkan tahap kecekapan dan keberkesanan LZS dalam mengenalpasti potensi pembayaran zakat perniagaan seterusnya merencana program yang bersesuaian kepada usahawan Muslim di Selangor. Akhirnya dapat meningkatkan jumlah kutipan dan agihan zakat di negeri Selangor khususnya dan negeri-negeri lain amnya.

\section{METODOLOGI KAJIAN}

Analisis kajian ini dilakukan kepada usahawan Islam dan syarikat Islam di seluruh daerah Sepang, Selangor. Usahawan dipilih sebagai responden kajian kerana usahawan merupakan penggerak utama dalam membangunkan ekonomi sesebuah negara. ${ }^{37}$ Bukan itu sahaja, al-Quran secara terang telah mengajak manusia untuk mencari pekerjaan di muka bumi ini khususnya menceburi bidang perniagaan dan keusahawanan. Persampelan dilakukan menggunakan kaedah rawak mudah dengan mengedarkan soal selidik yang mengandungi 11 soalan demografi dan 25 soalan pemboleh ubah ke atas 150 usahawan di premis perniagaan mereka mengikut mukim dan bandar di Daerah Sepang. Kajian juga telah berjaya menemu bual beberapa usahawan di program usahawan anjuran LZS daerah Sepang. Soal selidik kajian dibahagikan kepada tiga bahagian iaitu Bahagian A yang berkaitan latar belakang responden. Manakala di Bahagian B pula, soal selidik tertumpu kepada faktor yang mempengaruhi pembayaran zakat perniagaan termasuklah berkaitan faktor imej korporat. Bahagian $\mathrm{C}$ adalah soalan berkaitan persepsi responden terhadap perkhidmatan keseluruhan oleh LZS. Kesemua soalan di

37 Minniti, M., 'Entrepreneurial Activity and Economic Growth,' Global Business \& Economic Review, 1/1 (1999): 31-42. 
bahagian $\mathrm{B}$ dan bahagian $\mathrm{C}$ adalah merupakan pemboleh ubah yang dikaji dalam bentuk skala likert iaitu bernilai 1 sekiranya persepsi responden adalah sangat tidak bersetuju hingga ke nilai 5 iaitu persepsi responden adalah sangat setuju. Sebanyak 150 borang soal selidik diedarkan dan hanya 137 responden yang mengembalikan soal selidik. Sebanyak 129 borang soal selidik yang boleh digunakan dan dianalisis di dalam kajian ini.

\section{Spesifikasi Model dan Kaedah Analisis Data}

Kajian ini cuba menganggar kebarangkalian wujud hubungan antara lima faktor utama terutamanya faktor imej korporat usahawan yang dijangkakan mempengaruhi pembayaran zakat perniagaan menggunakan regresi logistik. Namun sebelum itu, ujian analisis faktor (EFA) dilakukan bertujuan untuk memastikan semua faktor penyumbang kepada setiap pemboleh ubah utama mempunyai nilai varians yang tinggi untuk memastikan kesahan sesebuah pemboleh ubah. Alat analisis yang telah digunakan ialah ujian Kaiser-MeyerOlkin (KMO) dan ujian keseferaan Bartlett untuk menguji spesifikasi yang dikehendaki dalam sesuatu model. Akhirnya analisis korelasi dan regresi logistik akan digunakan untuk melihat apakah faktor penentu kebarangkalian yang mempengaruhi pembayaran zakat perniagaan. Dalam membentuk model regresi, beberapa pemboleh ubah bebas yang dijangkakan berhubung dengan pemboleh ubah bersandar secara teori perlu dimasukkan.

Satu model akan dibentuk di mana pemboleh ubah bersandar dalam model berbentuk binari iaitu sama ada usahawan membayar zakat perniagaan atau tidak. Memandangkan pemboleh ubah bersandar berbentuk binari dan pada masa yang sama terdapat pemboleh ubah bebas yang digunakan berbentuk dami, maka kedua-dua model ini sesuai dianggarkan dengan menggunakan model regresi logistik. Oleh itu, kajian ini akan mengaplikasikan satu model berdasarkan kajian Sanep et al. (2006). ${ }^{38}$ Ini adalah kerana model tersebut mempunyai banyak persamaan dengan kajian ini dalam menganggarkan beberapa pemboleh ubah bersandar yang berbentuk binari dan terdapat beberapa pemboleh ubah bersandar yang berbentuk dami.

Oleh itu model yang dianggarkan secara umumnya dalam kajian ini adalah seperti berikut:

$$
\mathrm{P}_{\mathrm{i}}=\mathrm{E}(\mathrm{Y}=1 / \mathrm{X})=1 /\left(1+\mathrm{e}^{-\mathrm{z}}\right)
$$

38 Sanep Ahmad, Hairunnizam Wahid \& Adnan Mohamad, 'Penswastaan Institusi Zakat dan Kesannya Terhadap Pembayaran Secara Formal di Malaysia,' International Journal of Management Studies, 13/2 (2006): 175-196. 
Di mana: $\mathrm{P}_{\mathrm{i}}$ adalah kepatuhan usahawan membayar zakat perniagaan atau tidak;

$\mathrm{Y}=1$ adalah usahawan yang membayar zakat perniagaan dan

$\mathrm{Y}=0$ bagi usahawan yang tidak membayar zakat perniagaan.

Justeru berdasarkan persamaan (1), kajian ini akan menguji beberapa pemboleh ubah yang dijangkakan mempengaruhi kepatuhan membayar zakat perniagaan $\left(\mathrm{P}_{\mathrm{i}}\right)$ iaitu:

$$
Z_{i}=\beta_{0}+\beta_{1} X_{1}+\beta_{2} X_{2}+\beta_{3} X_{3}+\ldots \ldots+\beta_{n} X_{n}
$$

$Z_{i}$ adalah satu fungsi $f(X)$ dengan $X$ adalah pemboleh ubah bebas yang dijangkakan iaitu jantina, umur pengusaha, tahap pendidikan pengusaha, untung bersih tahunan, sikap dan kefahaman pengusaha terhadap zakat, imej korporat, institusi zakat, kakitangan institusi dan undang-undang dan fatwa. Kesemua pemboleh ubah tersebut dikaji merujuk kepada beberapa kajian ${ }^{39}$ yang telah dilakukan sebelum ini. Kesemua pemboleh ubah dalam persamaan (2) akan diuji untuk menentukan manakah pemboleh ubah yang signifikan mempengaruhi pembayaran zakat perniagaan oleh usahawan. Berdasarkan Jadual 1, dan kesemua responden yang ditemu bual adalah terdiri daripada usahawan perempuan (69.8 peratus), berumur antara 31-40 tahun (35.9 peratus), berkelulusan STPM dan ke bawah (76 peratus), menjalankan perniagaan tunggal atau enterprise (40.3 peratus), berkeuntungan bersih setahun antara RM1,000 hingga RM9,999 (32.6 peratus), menjalankan perniagaan di dalam tempoh 1 hingga 4 tahun (25,6 peratus) dan akhirnya ramai antara responden yang dikaji menjalankan jenis perniagaan berkaitan jualan/ pemasaran/ perdagangan produk (27.9 peratus).

39 Hairunnizam Wahid \& Sanep Ahmad, 'Faktor Mepengaruhi Tahap Keyakinan Agihan Zakat: Kajian Terhadap Masyarakat Islam di Selangor,' Jurnal Ekonomi Malaysia, 48/2 (2014): 41-50. 
Jadual 1: Demografi Usahawan/Syarikat

\begin{tabular}{|c|c|c|}
\hline Item & Kekerapan & Peratusan \\
\hline \multicolumn{3}{|l|}{ Kategori Perniagaan: } \\
\hline Tunggal/ Enterprise & 52 & 40.3 \\
\hline Perkongsian & 2 & 1.6 \\
\hline Sendirian Berhad/ Berhad & 20 & 15.5 \\
\hline Lain-lain & 55 & 30.2 \\
\hline \multicolumn{3}{|l|}{ Keuntungan Bersih } \\
\hline \multicolumn{3}{|l|}{ Setahun: } \\
\hline RM1,000 - RM,9999 & 42 & 32.6 \\
\hline RM10,000 - RM49,999 & 28 & 21.7 \\
\hline RM50,000 - RM99,999 & 6 & 4.7 \\
\hline RM100,000 - RM149,999 & 1 & 0.8 \\
\hline RM150,000 - RM199,999 & 9 & 7.0 \\
\hline RM200,000 - RM249,999 & 6 & 4.7 \\
\hline RM250,000 ke atas & 33 & 25.6 \\
\hline \multicolumn{3}{|l|}{ Tempoh Perniagaan: } \\
\hline 1 tahun -4 tahun & 32 & 24.8 \\
\hline 5 tahun -9 tahun & 8 & 6.2 \\
\hline 10 tahun - 14 tahun & 6 & 4.7 \\
\hline 15 tahun - 19 tahun & 4 & 3.1 \\
\hline 20 tahun - 24 tahun & 1 & 0.8 \\
\hline 25 tahun - 29 tahun & 6 & 4.7 \\
\hline 30 tahun ke atas & 4 & 3.1 \\
\hline \multicolumn{3}{|l|}{ Jenis Perniagaan: } \\
\hline Jualan/ Pemasaran/ & 36 & 27.9 \\
\hline \multicolumn{3}{|l|}{ Perdagangan } \\
\hline Perkhidmatan & 25 & 19.4 \\
\hline Perkilangan/ Kejuruteraan & 2 & 1.6 \\
\hline Pertanian/ Perladangan & 2 & 1.6 \\
\hline Penternakan & 7 & 5.4 \\
\hline \multicolumn{3}{|l|}{ Perniagaan Pelbagai/ } \\
\hline Campuran & 13 & 10.1 \\
\hline Kewangan & 1 & 0.8 \\
\hline Lain-Lain & 10 & 7.8 \\
\hline
\end{tabular}

Sumber: Data soal selidik. 


\section{HASIL KAJIAN}

Berdasarkan Jadual 2, majoriti usahawan yang menjadi responden dalam kajian ini tidak pernah menunaikan zakat perniagaan iaitu hampir 65.9 peratus berbanding 34.1 peratus yang membayar zakat perniagaan. Ini menggambarkan bahawa, kutipan zakat perniagaan di Sepang, Selangor masih boleh dipertingkatkan sejajar dengan penambahan bilangan asnaf yang perlu dibantu oleh LZS khususnya di cawangan Sepang. Usaha yang berterusan perlu dilakukan oleh LZS bagi memastikan lebih ramai usahawan Muslim menunaikan zakat. Banyak aktiviti turun padang boleh dilakukan seperti pembukaan kaunter sementara di kawasan-kawasan berpotensi, mengiklankan dan mempromosi perkhidmatan rundingan dan taksiran, menggunakan masjid sebagai pusat kegiatan zakat dan menjalinkan hubungan erat dengan pihak pimpinan setempat. Institusi Zakat perlu memiliki dana yang cukup melalui peluasan ruang kewajipan berzakat dengan mengutip zakat daripada harta yang zahir mahupun batin. $^{40}$

Jadual 2: Status Pembayaran Zakat

\begin{tabular}{lcc}
\hline \multicolumn{1}{c}{ Item } & Kekerapan & Peratusan \\
\hline Pernah & 44 & 34.1 \\
Tidak Pernah & 85 & 65.9 \\
\hline
\end{tabular}

Sumber: Data soal selidik.

Justeru, untuk meningkatkan kesedaran membayar zakat perniagaan, beberapa faktor penyumbang telah dibentukkan menggunakan analisis faktor (EFA) kepada setiap pemboleh ubah utama iaitu faktor sikap, faktor imej korporat, faktor institusi zakat, faktor kakitangan institusi zakat dan akhirnya faktor undang-undang dan fatwa. Kesemua lima faktor ini mempunyai beberapa item yang dijelaskan oleh beberapa pemboleh ubah berkenaan secara terperinci. Ini dapat dilihat di Jadual 3. Kajian ini menganalisis kelima-lima faktor beserta item yang terlibat untuk melihat manakah antara item-item berkenaan mempengaruhi setiap pemboleh ubah yang dikaji dengan melihat kepada nilai faktor muatan dan komunaliti setiap item. Perlu dinyatakan juga adalah penting untuk mengesahkan kesesuaian item tersebut dalam kelompok faktor yang dikaji. Nilai muatan dan komunaliti yang tertinggi menunjukkan sumbangan yang terbesar terhadap pemboleh ubah yang dikaji. Kajian mendapati kesemua nilai muatan dan ujian KMO dan ujian keseferaan Bartlett memenuhi spesifikasi yang dikehendaki dalam sesuatu model. Kajian ini

40 YusufQaradhawi, Institusi Zakat Masa Kini, Bagaimana Menjayakannya (Kajang: Pusat Zakat Selangor, 2001), 1. 
seterusnya akan melakukan analisis korelasi sebelum membina sesuatu model regresi. Kajian mendapati kesemua pemboleh ubah adalah berhubungan secara signifikan pada aras keertian 5 peratus dan mempunyai nilai koefisien positif antara kelima-lima kelompok faktor atau pemboleh ubah (lihat Jadual 4). Oleh itu, langkah seterusnya, kajian ini menyarankan agar model ini boleh dianalisis menggunakan analisis regresi.

Jadual 3: Hasil Ujian daripada Analisis Faktor

\begin{tabular}{|c|c|c|c|c|}
\hline Kelompok Faktor & $\begin{array}{c}\text { Muatan } \\
\text { Faktor }\end{array}$ & Min & $\begin{array}{c}\text { Kaiser- } \\
\text { Meyer-Olkin }\end{array}$ & $\begin{array}{c}\text { Varians } \\
\text { Keseluruhan } \\
(\%)\end{array}$ \\
\hline $\begin{array}{l}\text { Sikap } \\
\text { (1) Zakat membawa berkat } \\
\text { (2) Mesti membersihkan harta } \\
\text { dengan berzakat } \\
\text { (3) Tanggungjawab membantu } \\
\text { golongan memerlukan }\end{array}$ & $\begin{array}{l}0.924 \\
0.900 \\
0.928\end{array}$ & $\begin{array}{l}4.62 \\
4.50 \\
4.64\end{array}$ & $0.848^{*}$ & 69.52 \\
\hline $\begin{array}{l}\text { Imej Korporat } \\
\text { (1) Imej lebih baik di kalangan } \\
\text { masyarakat dan pemerintah } \\
\text { (2) Menampakkan perbezaan dengan } \\
\text { pesaing } \\
\text { (3) Meningkatkan keyakinan dan } \\
\text { kesetiaan pelanggan }\end{array}$ & $\begin{array}{l}0.885 \\
0.886 \\
0.897\end{array}$ & $\begin{array}{l}4.25 \\
4.12 \\
4.14\end{array}$ & $0.779 *$ & 72.52 \\
\hline $\begin{array}{l}\text { Institusi Zakat } \\
\text { (1) Promosi dan perkhidmatan yang } \\
\text { memuaskan } \\
\text { (2) Kemudahan kaedah bayaran yang } \\
\text { baik } \\
\text { (3) Imej korporat yang baik dan } \\
\text { berkesan }\end{array}$ & $\begin{array}{l}0.927 \\
0.941\end{array}$ & 4.16 & $0.881^{*}$ & 82.63 \\
\hline $\begin{array}{l}\text { Kakitangan Institusi Zakat } \\
\text { (1) Berpuas hati dengan ilmu, } \\
\text { kredibiliti, amanah dan ketelusan } \\
\text { (2) Berpuas hati dengan imej } \\
\text { korporat pakaian dan komunikasi } \\
\text { berbanding imej klasik } \\
\text { (3) Berpuas hati dengan akhlak }\end{array}$ & $\begin{array}{l}0.909 \\
0.918 \\
0.907\end{array}$ & $\begin{array}{l}4.02 \\
4.03 \\
4.02\end{array}$ & $0.902 *$ & 82.03 \\
\hline
\end{tabular}




\begin{tabular}{lcccc}
\hline \multicolumn{1}{c}{ Kelompok Faktor } & $\begin{array}{c}\text { Muatan } \\
\text { Faktor }\end{array}$ & Min & $\begin{array}{c}\text { Kaiser- } \\
\text { Meyer-Olkin }\end{array}$ & $\begin{array}{c}\text { Varians } \\
\text { Keseluruhan } \\
\text { (\%) }\end{array}$ \\
\hline $\begin{array}{l}\text { Undang-undang dan Fatwa } \\
\text { (1) Bimbang dikenakan tindakan }\end{array}$ & 0.800 & 3.75 & $0.705^{*}$ & 57.78 \\
$\begin{array}{l}\text { undang-undang } \\
\begin{array}{l}\text { (2) Memastikan tidak terlepas } \\
\text { mendapat keistimewaan pemerintah }\end{array}\end{array}$ & 0.884 & 3.60 & & \\
$\begin{array}{l}\text { (3) Takut dianggap berdosa dengan } \\
\text { pemerintah }\end{array}$ & 0.866 & 3.68 & & \\
\hline
\end{tabular}

Nota: Min berdasarkan nilai skala Likert; nilai $1=$ sangat tidak setuju hingga nilai $5=$ sangat setuju *Bartlett's Test of Sphericity: signifikan pada aras keertian $1 \%$

Sumber: Data soal selidik.

Jadual 4: Korelasi antara Kelompok Faktor

\begin{tabular}{lccccc}
\hline \multicolumn{1}{c}{ Kelompok } & Sikap & $\begin{array}{c}\text { Imej } \\
\text { Korporat }\end{array}$ & $\begin{array}{c}\text { Institusi } \\
\text { zakat }\end{array}$ & Kakitangan & Fatwa \\
\hline (1) Sikap & 1 & & & & \\
(2) Imej Korporat & 0.484 & 1 & & & \\
(3) Institusi zakat & 0.361 & 0.461 & 1 & & \\
(4) Kakitangan & 0.322 & 0.233 & 0.609 & 1 & 1 \\
(5) Fatwa & 0.280 & 0.392 & 0.184 & 0.250 & 1 \\
\hline
\end{tabular}

Nota: Kesemua pemboleh ubah adalah signifikan pada aras keertian 5\%

Sumber: Data soal selidik.

Jadual 5 menunjukkan klasifikasi model yang menunjukkan kesahan respon daripada usahawan yang dikaji. Secara keseluruhannya lebih 77.6 peratus disahkan jawapan usahawan adalah benar daripada model yang dikaji. Ini menunjukkan jawapan yang diberikan adalah disahkan benar dan amat sesuai untuk dianalisis. 
Jadual 5: Klasifikasi Regresi Logistik

\begin{tabular}{lcc}
\hline \multicolumn{1}{c}{ Pemerhatian } & \multicolumn{2}{c}{ Diramalkan } \\
\hline & Bayar Zakat & Tidak Bayar Zakat \\
Bayar Zakat & 6 & 10 \\
Tidak Bayar zakat & 5 & 46 \\
\hline
\end{tabular}

Nota: Nilai batasan adalah 0.500

Peratusan Betul: bayar zakat $=37.5 \%$; tidak bayar zakat $=90.2 \%$;

Keseluruhan $=77.6 \%$

Sumber: Data soal selidik.

Berdasarkan Jadual 6, model telah dibentuk dan dianalisis menggunakan analisis regresi logistik. Jika dilihat kepada nilai koefisien, hanya tiga pemboleh ubah yang signifikan, iaitu faktor jantina usahawan, umur usahawan dan imej korporat syarikat masing-masing signifikan pada aras keertian 10 peratus. Ujian padanan model menggunakan kaedah Hosmer and Lemeshow mencatatkan nilai Chi-Square sebanyak 4.95 (sig=0.762) dengan 8 darjah kebebasan. Kedudukan ini menunjukkan bahawa model mempunyai padanan yang baik dengan data. Namun begitu nilai $\mathrm{R}^{2}$ pula yang menunjukkan variasi kesemua pemboleh ubah kepada model dalam lingkungan sekitar 24.7 peratus hingga 37 peratus berasaaskan Cox and Snell $\mathrm{R}^{2}$ dan Nagelkerke $\mathrm{R}^{2}$. Ini menunjukkan variasi pebolehubah bebas bagi model adalah agak besar menerangkan pemboleh ubah bersandar.

Hasil kajian ini jelas menunjukkan beberapa pemboleh ubah yang signifikan dan perlu diberi perhatian berdasarkan pemerhatian terhadap kedua-dua model ini. (1) Faktor jantina iaitu lelaki adalah berhubungan secara positif dan signifikan dalam model menunjukkan ia adalah pemboleh ubah yang penting kebarangkalian para usahawan membayar zakat perniagaan (2) Faktor umur juga menunjukkan ia adalah faktor yang signifikan dalam model. Kebarangkalian usahawan Muslim membayar zakat perniagaan adalah mereka yang semakin berumur berbanding usahawan muda. (3) Faktor imej korporat menunjukkan ia adalah faktor yang signifikan pada aras keertian 10 peratus. Ia jelas menyokong hipotesis kajian iaitu faktor imej korporat adalah signifikan mempengaruhi kebarangkalian usahawan Muslim membayar zakat perniagaan. Namun begitu, nilai koefisien yang agak tinggi dan bernilai negatif menunjukkan semakin rendah imej korporat yang ingin ditonjolkan, semakin tinggi kebarangkalian usahawan membayar zakat. Hasil kajian ini menunjukkan sekiranya faktor imej korporat meningkat sebanyak 1 unit, kebarangkalian usahawan membayar zakat perniagaan adalah menurun sebanyak 2.6 peratus. 
Hasil kajian ini menyokong hipotesis dan kajian lepas ${ }^{41}$ bahawa ia merupakan pemboleh ubah yang signifikan namun tidak menyokong hipotesis di mana ia sepatutnya berhubungan secara positif dengan kebarangkalian membayar zakat perniagaan.

Jadual 6: Hasil Regresi

\begin{tabular}{lc}
\hline \multicolumn{1}{c}{ Pemboleh ubah } & Nilai Koefisien \\
\hline Konstan & $-7.838^{*}$ \\
Jantina (1) & $(3.948)$ \\
& $2.691^{*}$ \\
Umur & $(1.041)$ \\
Tahap Pendidikan & $0.095^{*}$ \\
& $(0.042)$ \\
Untung bersih tahunan & 0.144 \\
Sikap & $(0.283)$ \\
& 0.058 \\
Imej Korporat & $(0.240)$ \\
Institusi zakat & 0.968 \\
Kakitangan LZS & $(0.791)$ \\
Fatwa & $-1.026^{*}$ \\
& $(0.584)$ \\
Hosmer and Lemeshow Test $\left(\chi^{2}\right)$ & 0.422 \\
Cox \& Snell R & $(0.786)$ \\
Nagelkerke R ${ }^{2}$ & -0.579 \\
\hline
\end{tabular}

Nota: ( ) ralat piawai

(1) dami lelaki

Model regresi logistik. Pemboleh ubah bersandar : Bayaran zakat perniagaan (1)

ns tidak signifikan

* Signifikan pada aras keertian 10\%

Sumber: Data soal selidik.

${ }_{41}$ Bahtiar M., Hassan A. B. \& Nik Adzrieman A. R., 'Relationship Between Corporate Identity and Corporate Reputation: A Case of A Malaysian Higher Education Sector,' Jurnal Manajemen Pemasaran, 2/2 (2007): 81-89. 


\section{PERBINCANGAN DAN IMPLIKASI DASAR}

Tidak boleh dinafikan bahawa pembayaran zakat yang dilakukan oleh seseorang usahawan Muslim berkait rapat dengan tujuan untuk menggambarkan imej korporat yang baik dalam kalangan masyarakat. Ini menyokong kajian ${ }^{42}$ yang menyatakan imej korporat atau identiti korporat bergerak seiring dengan aktiviti komunikasi korporat. Setiap organisasi akan menunjukkan imej korporat mereka melalui logo, misi, visi, budaya kerja, nilai, aktiviti masyarakat, tanggungjawab sosial dan sebagainya. Namun, kajian ini berpendapat wujud hubungan negatif antara pemboleh ubah imej korporat dan pembayaran zakat perniagaan. Ini menunjukkan, usahawan Muslim yang telah membayar zakat berniat semata-mata kerana Allah SWT dan ingin mendapat untung rohani iaitu pahala di akhirat. Namun demikian, akibat tindakan usahawan membayar zakat perniagaan sebenarnya akan menjana keuntungan ekonomi melalui untung yang diraih daripada perniagaan yang juga akhirnya akan meningkatkan imej korporat usahawan serta syarikat tersebut.

Namun begitu hasil kajian ini memberikan satu implikasi yang penting iaitu imej korporat adalah penting untuk memotivasikan usahawan Muslim yang masih belum membayar zakat perniagaan. Sasaran LZS sebenarnya adalah menarik minat usahawan Muslim yang masih belum membayar zakat perniagaan dan tindakan ini perlu bermula dengan memberikan satu insentif berbentuk ekonomi iaitu melalui pengiktirafan dan imej korporat. Ini kerana walaupun pada awalnya seseorang usahawan dan syarikat inginkan insentif ekonomi berbentuk pengiktirafan melalui imej korporat, namun akibat perlakuan usahawan tersebut membayar zakat secara berulang-ulang, akhirnya akan melahirkan gelagat kepatuhan membayar zakat yang ikhlas kerana Allah SWT, mengharapkan untung rohani serta keredhaaan daripada Allah SWT. Namun, perlu difahami bahawa akibat tindakan usahawan tersebut, keberkatan akan diberikan oleh Allah SWT akibat tindakannya yang akhirnya usahawan tersebut serta syarikat akan mendapat al-falah, iaitu kejayaan di dunia melalui untung ekonomi dan kejayaan di akhirat melalui untung rohani.

Kajian ini juga berpendapat adalah tidak dianggap ganjil sekiranya tanggungjawab menunaikan zakat perniagaan dilabel sebagai satu program tanggungjawab sosial syarikat (CSR) seperti dilakukan oleh syarikat korporat. Namun perlu ditanamkan disanubari usahawan Muslim bahawa tujuan dan niat seseorang yang ingin berzakat mestilah kerana Allah semata-mata.

42 Bahtiar M., Hassan A. B. \& Nik Adzrieman A. R., 'Relationship Between Corporate Identity and Corporate Reputation: A Case of A Malaysian Higher Education Sector,' 81-89. 
Namun apa yang membezakan tindakannya ialah cara dan kaedah seseorang untuk menunaikan zakat. Cara dan kaedah inilah jika disertakan dengan niat ikhlas kerana Allah SWT, dan terbukti kejayaannya melalui untung ekonomi dan keberkatan yang diraih, maka ia boleh menjadi faktor pencetus motivasi kepada usahawan dan syarikat korporat yang lain untuk menunaikan zakat. Ia sebenarnya tidak bercanggah dengan firman Allah SWT dalam al-Quran:

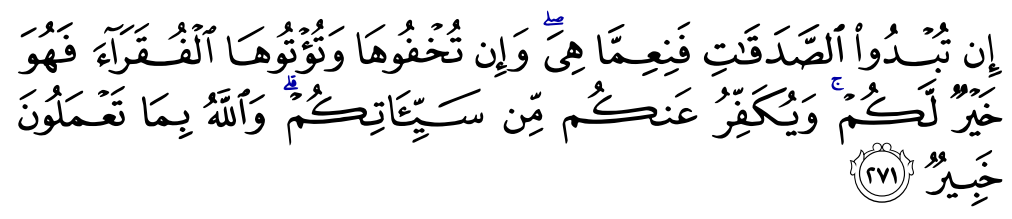

"Jika kamu lahirkan sedeqah (zakat), maka itulah sebaik-baiknya, dan jika kamu sembunyikan dan kamu berikan kepada orangorang fakir, maka itulah yang lebih baik bagimu dan menutupi kesalahanmu, dan Allah Maha Mengetahui apa-apa yang kamu kerjakan."

(Surah al-Baqarah, 2: 271)

Rajah 2: Kelebihan Menunaikan Zakat

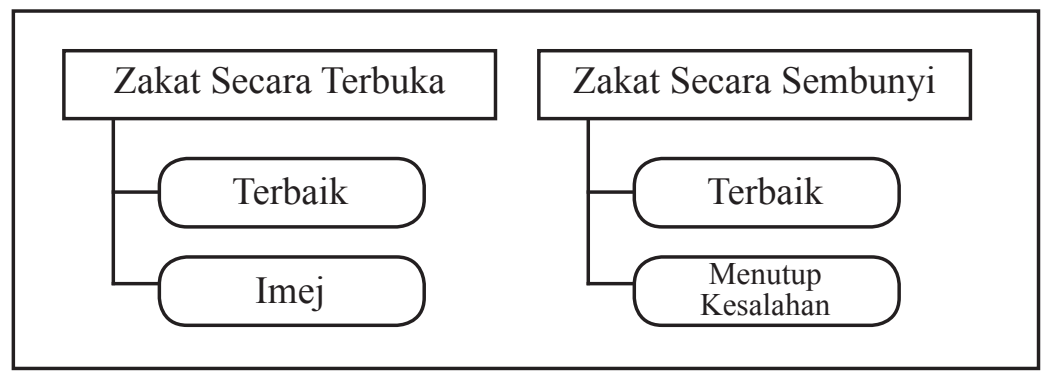

Sumber: Mahmud Yunus, Tafsir Quran Karim (Jakarta: Pt. Hidakarya Agung, 1969).

Rajah 2 menyimpulkan kelebihan seseorang usahawan dalam menunaikan zakat seperti mana yang dinyatakan di dalam Surah al-Baqarah ayat 271. Ia selari dengan kehendak dan sifat semulajadi seseorang usahawan itu sendiri. Malah kajian-kajian sebelum ini juga menyokong bahawa imej korporat antara faktor yang diambil berat oleh seseorang usahawan. Apatah lagi apabila mereka mempunyai produk dan perkhidmatan yang digunakan oleh setiap lapisan masyarakat. Sudah tentulah masyarakat mengharapkan sumbangan tertentu 
boleh diberikan syarikat atau usahawan yang telah berjaya dan menjana keuntungan setiap tahun. Maka pembayaran zakat dilihat oleh seseorang usahawan sebagai salah satu saluran dalam mempromosikan nama mereka dalam kalangan khalayak awam. Secara tidak langsung, cara penunaian ini akan memberikan kesan imej korporat tersendiri kepada seseorang usahawan. LZS dicadangkan agar mempromosikan pembayaran zakat perniagaan sebagai salah satu program tanggungjawab sosial Islamik dengan istilah seperti Company Zakat Responsibility Programe (CZRP). Berikut adalah beberapa cadangan kepada LZS dalam mempromosi imej korporat ini seperti di Rajah 3. Sudah tiba masanya umat Islam mempromosikan semula segala-galanya tentang Islam agar ia dilihat sebagai sebuah agama sejagat suatu hari nanti.

Rajah 3: Cadangan Mempromosikan Imej Korporat

\begin{tabular}{|c|c|}
\hline & Penghargaan \\
\hline & bertandatangan \\
\hline & $\begin{array}{l}\text { Pembayar Zakat Perniagaan diraikan di dalam Majlis } \\
\text { Bayaran Rasmi yang dihadiri Sultan atau Menteri Besar. }\end{array}$ \\
\hline & $\begin{array}{l}\text { Menjemput Pembayar Zakat Perniagaan sebagai tetamu } \\
\text { khas program agihan bantuan asnaf fakir miskin. }\end{array}$ \\
\hline & $\begin{array}{l}\text { Menyediakan pegawai khas yang boleh berurusan secara } \\
\text { peribadi dengan usahawan dalam urusan penerangan, } \\
\text { taksiran, pembayaran dan khidmat selepas jualan. }\end{array}$ \\
\hline & 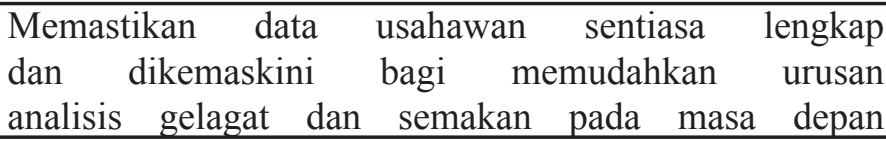 \\
\hline
\end{tabular}

Sumber: Pandangan responden dalam borang soal selidik.

\section{KESIMPULAN}

Setiap faktor yang dikaji menunjukkan ia amat penting mempengaruhi pembayaran zakat perniagaan oleh usahawan Muslim di Sepang. Faktor imej korporat perlu diberi penekanan oleh pihak LZS memandangkan ia amat besar pengaruhnya terhadap niat dan kehendak seseorang usahawan untuk menunaikan zakat. Ini kemudiannya diikuti oleh faktor institusi zakat dan kakitangan institusi zakat. Walaupun faktor institusi zakat, kakitangan serta undang-undang dan fatwa menunjukkan secara statistiknya mempunyai pengaruh tidak signifikan kepada pembayaran zakat, ia juga perlu diberi perhatian. Pihak LZS perlu meningkatkan lagi usaha dalam memberi 
kefahaman dan menanamkan sikap mengutamakan berzakat dalam kalangan usahawan Muslim agar kutipan zakat dapat ditingkatkan seterusnya mampu digunakan untuk manfaat lebih ramai asnaf. Pihak kerajaan mahupun LZS juga boleh memainkan peranan penting dalam usaha ini dengan menghargai dan memberikan lebih banyak insentif kepada usahawan yang istiqamah di dalam menunaikan zakat. Banyak saluran yang boleh digunakan bagi menghebahkan dan menwar-warkan keupayaan usahawan Muslim tersebut termasuklah cadangan memberikan satu logo pengiktirafan pembayar zakat perniagaan yang konsisten. Malah tidak keterlaluan jika penunaian zakat perniagaan digariskan sebagai pencapaian matlamat dan tanda aras seseorang usahawan Muslim yang berjaya di dunia dan di akhirat.

\section{RUJUKAN}

Abdul Hakim Amir Osman, 'Potensi Pembayar dan Kutipan Zakat di Malaysia,' (Kertas Kerja Pembentangan, Konvensyen Zakat dan Cukai Peringkat Kebangsaan di PWTC, Kuala Lumpur, 22- 24 Mei 2007).

Ahmad Abdul Aziz Al-Mazini, Panduan Mengeluarkan Zakat (Petaling Jaya: Al-Rahmaniah, 1989).

Arifin Md. Salleh et al., Asas Sumber-Sumber Zakat di Malaysia: Satu Penerokaan (Alor Gajah: URDC UiTM, 2006).

Azizah Dolah et al., Kajian Terhadap Amalan Perakaunan Pengurusan dalam Aspek Agihan Dana Zakat dari Perspektif Pengurus Zakat (Shah Alam: IRDC UiTM, 2004).

Bahtiar M., Hassan A. B. \& Nik Adzrieman A. R., 'Relationship Between Corporate Identity and Corporate Reputation: A Case of A Malaysian Higher Education Sector,' Jurnal Manajemen Pemasaran, $2 / 2$ (2007): 81-89.

Hairunnizam Wahid \& Sanep Ahmad, 'Faktor Mempengaruhi Tahap Keyakinan Agihan Zakat: Kajian Terhadap Masyarakat Islam di Selangor,' Jurnal Ekonomi Malaysia, 48/2 (2014): 41-50.

Hairunnizam Wahid \& Radiah Abdul Kader, 'Localization of Malaysian Zakat Distribution: Perceptions of Amil and Zakat Recipients,' Proceedings of Seventh International Conference. The Tawhidi Epistemology: Zakat and Waqf Economy, ed. Abdul Ghafar et al. (Bangi: UKM, 2010), 461484.

Hairunnizam Wahid, Sanep Ahmad \& Radiah Abdul Kader, 'Pengagihan Zakat oleh Institusi Zakat kepada Lapan Asnaf: Kajian di Malaysia,' Jurnal Pengurusan JAWHAR, 4/1 (2010): 141-170. 
Hairunnizam Wahid, Sanep Ahmad \& Radiah Abdul Kader, 'Pengagihan Zakat oleh Institusi Zakat di Malaysia: Mengapakah Masyarakat Islam Tidak Berpuashati?' Jurnal Syariah, 17/1 (2009): 89-112.

Hairunnizam Wahid, Sanep Ahmad, Mohd Ali Mohd Noor, 'Kesedaran Membayar Zakat Pendapatan di Malaysia,' Islamiyyat, 29 (2007): 5370 .

Horowitz M.J., Image Formation and Cognition (US: Appleton Century Crofts, 1970).

Jabatan Kemajuan Islam Malaysia, Panduan Zakat di Malaysia (Kuala Lumpur: JAKIM, 2001).

Lembaga Zakat Selangor, http://www.e-zakat.com.my/sejarah-lzs/, dicapai pada 5 November 2014.

Mahmood Zuhdi Abd. Majid, 'Pemantapan Sistem Zakat dan Cukai ke Arah Kemajuan Ekonomi Ummah,' (Kertas Kerja Pembentangan, Konvensyen Zakat \& Cukai Peringkat Kebangsaan di PWTC, Kuala Lumpur, 22- 24 Mei 2007).

Mahmud Yunus, Tafsir Quran Karim (Jakarta: Pt. Hidakarya Agung, 1969).

Marken, G. A., 'Corporate Image - We all Have One, But Few Work to Protect and Project It,' Public Relations Quarterly, 35/1 (1990): 21-24.

Merril, J.C., 'The Image of the United States in ten Mexican Dailies,' Journalism \& Mass Communication Quarterly, 39/2 (1962): 203-209.

Minniti, M., 'Entrepreneurial Activity and Economic Growth,' Global Business \& Economic Review, 1/1 (1999): 31-42.

Mujaini Tarimin, Kontinuiti Pembangunan Zakat di Malaysia (Shah Alam: Lembaga Zakat Selangor, 2011).

Patmawati Ibrahim, 'Peranan Agihan Zakat dalam Meningkatkan Tahap Ekonomi Ummah,' (Kertas Kerja Pembentangan, Konvensyen Zakat dan Cukai Peringkat Kebangsaan di PWTC, Kuala Lumpur, 22- 24 Mei 2007).

Ram Al Jaffri Saad, Kamil Md. Idris \& Zainol Bidin, 'Peraturan Pembayaran Zakat kepada Institusi Zakat: Sikap Peniaga dan Kesannya Terhadap Gelagat Pembayaran Zakat Perniagaan,' Jurnal Syariah, 17/3 (2009): 610.

Rosbi Abd Rahman \& Sanep Ahmad, 'Pengukuran Keberkesanan Agihan Zakat: Perspektif Maqasid Syariah,' Persidangan Antarabangsa Ke-7, Tawhidi Epistemologi: Zakat and Waqf Economy (Bangi: UKM, 2010), 448. 
Sanep Ahmad \& Hairunnizam Wahid, 'Penerimaan dan Tanggapan Masyarakat terhadap Sumber Zakat Harta yang Diikhtilaf,' Islamiyyat, 27 (2005): 45-65.

Sanep Ahmad \& Hairunnizam Wahid, 'Persepsi Agihan Zakat dan Kesannya terhadap Pembayaran Zakat melalui Institusi Formal,' Jurnal Ekonomi Malaysia, 39 (2005): 53-69.

Sanep Ahmad, Hairunnizam Wahid \& Adnan Mohamad, 'Penswastaan Institusi Zakat dan Kesannya Terhadap Pembayaran Secara Formal di Malaysia,' International Journal of Management Studies, 13/2 (2006): 175-196.

Webster, J.G \& Wakshlag J.J., 'A Theory of Television Program Choice,' Communication Research, 10/4 (1983): 430-446.

Yusuf Qaradhawi, Institusi Zakat Masa Kini, Bagaimana Menjayakannya (Kajang: Pusat Zakat Selangor, 2001).

Zahri Hamat, 'Perakaunan Zakat Perniagaan di Malaysia: Satu Kajian Rintis Pendapat Cendekiawan Zakat,' (Tesis Ph.D, Pusat Pengajian Sains Kemasyarakatan, USM Pulau Pinang, 2007).

Zulkifli Mohamad al-Bakri, Ahkam wa Fatawa al-Zakah, Pelbagai Hukum dan Fatwa Zakat (Bandar Baru Bangi: Darul Syakir Enterprise, 2010). 